\title{
CONTEÚDOS CULTURAIS-COGNITIVOS VERSUS PEDAGÓGICO-DIDÁTICO NA FORMAÇÃO DOCENTE EM GEOGRAFIA A PARTIR DA CATEGORIZAÇÃO DE QUESTÕES DO CURRÍCULO AVALIADO/ENADE (2005-2017)
}

\author{
Jéssica Gomes de Jesus Oliveira ${ }^{1}$ \\ Pedro Wagner Gonçalves²
}

\section{RESUMO}

Este artigo busca verificar qual dos modelos de formação docente proposto por Saviani (2009) - conteúdos culturais-cognitivos, com enfoque no domínio específico dos conteúdos; e pedagógicos-didáticos, preocupado com o ensino-aprendizagem está presente na organização curricular dos cursos de licenciatura em Geografia, investigando as questões do Exame Nacional de Desempenho dos Estudantes (ENADE) das edições de 2005, 2008, 2011, 2014 e 2017. Estas questões foram categorizadas seguindo a metodologia de análise de conteúdo entre "conhecimentos pedagógicos-didáticos", "Ensino de Geografia" e "conhecimentos técnicos-científicosgeográficos". As categorizações mostram que o modelo dos conteúdos culturaiscognitivos foi enfatizado em todas as edições. Ressalta-se que o ENADE como currículo avaliado pode ser um fator indutor de maior equilíbrio entre a formação técnico-científica e pedagógica, sendo preciso alterar a ênfase expressa nas questões das provas.

Palavras-chaves: Formação de professores; Professores de geografia - Formação; Exame Nacional de Desempenho dos Estudantes.

\section{CULTURAL COGNITIVE VERSUS DIDATICAL PEDAGOGICAL CONTENTS FOR TEACHER EDUCATION IN GEOGRAPHY FROM EVALUATED CURRICULUM BETWEEN 2005 AND 2017 BY MEANS OF CONTENT ANALYSIS}

\footnotetext{
ABSTRACT

This paper aims to describe what model dominates the evaluated curriculum for formation of the teachers of geography. Saviani (2009) has proposed two models to

${ }^{1}$ Graduada em bacharelado e licenciatura em Geografia pela Universidade Estadual de Campinas (2017), mestra em Ensino e História das Ciências da Terra pela Universidade Estadual de Campinas (2020). Professora de Geografia na rede pública da cidade de São Paulo e doutoranda em Ensino e História das Ciências da Terra pela Universidade Estadual de Campinas. Email: jessicagomes.jesusoliveira@gmail.com

${ }^{2}$ Graduado em Geologia pela Universidade de São Paulo (1982), Mestre em Educação pela Universidade Estadual de Campinas (1989), Doutor em Filosofia pela Universidade Estadual de Campinas (1997). Atualmente é professor Doutor no Instituto de Geociências - UNICAMP. E-mail: pedrog@ige.unicamp.br
} 
training teachers: cultural cognitive or didactic pedagogical. The first focuses on the specific domain of content, and the second is based on pedagogical and didactic content (concerned with teaching-learning). We examine the issues of the Brazilian Exams (ENADE, national exams done by students which finished undergraduate careers) occurred in 2005, 2008, 2011, 2014, and 2017. The questions of exams were categorized concerning the content analysis methodology. This has permitted us to identify: "pedagogical-didactic knowledge", "Teaching of Geography" and "technicalscientific-geographic knowledge". The categorizations show that the cultural-cognitive content model was emphasized in all editions. The ENADE is an evaluated curriculum and can be an inducing factor of greater balance between technical-scientific and pedagogical training. This is necessary to change the emphasis expressed in the questions of the tests.

Keywords: Teacher Education; Teacher Education of Geography; Politics of Curriculum.

\section{INTRODUÇÃO}

Este artigo apresenta um recorte da pesquisa realizada ao longo do mestrado por Oliveira (2020). Este trabalho parte da problemática da formação inicial de professores no Brasil, que historicamente priorizaram os conhecimentos específicos das disciplinas que seriam ministradas pelo futuro professor e deixaram em segundo plano ou até mesmo de lado os aspectos pedagógicos-didáticos, conforme apontado pelos referenciais teóricos Saviani (2009) e Libâneo (2015).

Para compreender como aconteceu essa dissociação na formação docente entre os aspectos pedagógicos-didáticos e teórico-científicos, é preciso considerar o processo histórico. A preocupação com a instrução popular se intensificou após a Revolução Francesa, e foi somente no século XIX que as Escolas Normais foram criadas como instituições com a função de preparar professores. No Brasil, a instrução básica das crianças somente foi pensada após a Independência do Brasil, e após a Proclamação da República surgiram as Escolas Normais criadas para serem responsáveis pela formação dos professores para as escolas primárias (SAVIANI, 2009).

Para Saviani (2009), historicamente no Brasil, é possível identificar dois modelos na formação docente:

a) modelo dos conteúdos culturais-cognitivos: para este modelo, a formação do professor se esgota na cultura geral e no domínio específico dos conteúdos da área de conhecimento correspondente à disciplina que irá lecionar.

b) modelo pedagógico-didático: contrapondo-se ao anterior, este modelo considera que a formação do professor propriamente dita só se completa com o efetivo preparo pedagógico didático (SAVIANI, 2009, p. 148-149)

De acordo com Saviani (2009), a partir da década de 1930, o primeiro modelo predominou nas universidades e demais instituições de ensino superior encarregadas da formação dos professores secundários ou especialistas; já o segundo modelo prevaleceu nas Escolas Normais responsáveis pela formação dos professores primários. 
Cabe ressaltar que, na década de 1930, o Decreto-Lei № 1190/1939 estabeleceu que as Faculdades de Filosofia, Ciências e Letras deveriam ofertar os Cursos Ordinários, que tinham a duração de três anos e conferiam o diploma de bacharel. Caso esse bacharel desejasse possuir o diploma de licenciatura, deveria realizar o curso de Didática, com duração de um ano. Nesse contexto, a formação docente foi denominada de "esquema 3+1", fazendo referência aos três anos do curso de bacharel somado ao um ano do curso de Didática (BRASIL, 1939).

Para Scheibe (1983), o "esquema 3+1" evidenciava que o título de bacharel estava ligado ao prestígio, e a licenciatura, atribuída por meio do curso de Didática, era considerada algo dispensável e desprestigiante. Sobre esse "esquema 3+1", a pesquisadora brasileira afirma que

A formação pedagógica nas licenciaturas reflete o caráter secundário e apenas subsidiário atribuído à educação e ao ensino no âmbito da universidade. Em geral, esta formação coloca-se como mero apêndice das diferentes formas de bacharelados desempenhando, na prática, o papel de garantir os requisitos burocráticos para o exercício do magistério (SCHEIBE, 1983, p. 31).

Na década de 1960, o "esquema 3+1" foi revogado. Ainda assim, no curso de licenciatura em Geografia, o "esquema 3+1" continuou caracterizando a formação inicial do professor de Geografia, como apontado por Moraes (2002), Pontuschka, Paganelli e Cacete (2009), Pontuschka (2012) e Callai (2013).

Sobre o processo formativo dos/das professores/as de Geografia, Pontuschka, Paganelli e Cacete (2009) criticam a ênfase nos conteúdos técnicos-científicos. As pesquisadoras revelam que os debates acadêmicos encobrem a concepção de que o professor aprende na prática. Nas palavras das pesquisadoras:

O modelo clássico de Formação desse profissional, que perdura até hoje, caracteriza-se por uma organização curricular que prevê a dois conjuntos de estudos, congregando, de um lado, técnico-científicas e, de outro, as disciplinas didático-(psico) pedagógicas. Esse formato tradicional ficou conhecido como "modelo $3+1$ ", ou seja, 3 anos de bacharelado mais um ano de formação pedagógica - que muitos consideravam como licenciatura-, acrescida de estágio supervisionado (PONTUSCHKA; PAGANELLI \& CACETE, 2009, p. 90).

Libâneo (2015) considera como um problema na organização curricular da formação profissional de professores a dissociação entre os conhecimentos disciplinares e os conhecimentos pedagógicos. Para o autor, essa separação é prejudicial, levando os docentes em seu exercício profissional a terem dificuldades para incorporar e articular o domínio dos conteúdos da disciplina e o domínio de saberes e habilidades para ensinar esses conteúdos.

Tendo a problemática acima delineada, o objetivo principal deste trabalho é verificar qual dos modelos de formação de professores proposto por Saviani (2009) conteúdos culturais-cognitivos, em que há enfoque no domínio específico dos conteúdos da área; e pedagógico-didático, com preocupação no ensinoaprendizagem - está presente na organização curricular dos cursos de licenciatura em Geografia.

Para isso, foi selecionado como objeto de interpretação e investigação o Exame Nacional de Desempenho dos Estudantes (ENADE), que é a avaliação padronizada e 
em larga escala do Ministério da Educação (MEC), aplicada para os estudantes de ensino superior no Brasil.

Segundo Freitas et al. (2009), a avaliação em larga escala é um instrumento de acompanhamento global das redes de ensino e possui como principal objetivo traçar séries históricas do desempenho dos sistemas escolares, o que permite verificar tendências ao longo do tempo e, a partir dos resultados, reorientar as políticas públicas educacionais. Essas provas seguem um padrão e possuem como instrumento de avaliação testes de proficiência e questionários aplicados conforme um sistema de avaliação ou matriz de referência.

Para identificar se há predominância nas questões do ENADE do modelo dos conteúdos culturais-cognitivos ou do modelo pedagógico-didático, foram categorizadas as questões discursivas e de múltipla escolha do ENADE para o curso de licenciatura em Geografia dos anos de 2005, 2008, 2011, 2014 e 2017 nas seguintes categorias: "questões sobre os conhecimentos pedagógicos-didáticos", "questões sobre o Ensino de Geografia" e "questões sobre os conhecimentos técnicos-científicos-geográficos", seguindo a metodologia qualitativa de análise de conteúdo baseada nas contribuições de Gibbs (2009) e Bardin (2016).

Este artigo é estruturado em quatro seções. A primeira seção apresenta a discussão conceitual sobre o termo currículo, baseado em Sacristán (2000), Goodson (2008) e Silva (2011), para delimitar o ENADE enquanto objeto de estudo como currículo avaliado (SACRISTÁN, 2000). Também é exposta uma breve descrição das edições do ENADE que avaliaram a área de Geografia, baseado em Jesus (2019) e Oliveira (2020).

Em seguida, é descrito o caminho metodológico percorrido ao longo do desenvolvimento desta pesquisa, baseado em Gibbs (2009) sobre a análise qualitativa de dados e da análise de conteúdo proposta por Bardin (2016), explicando-se o processo de categorização das questões conforme tipos de conhecimentos realizado por Oliveira (2020).

$\mathrm{Na}$ terceira seção, são apresentados os resultados desta pesquisa a partir da interpretação das questões específicas conforme as categorias de "questões sobre os conhecimentos pedagógicos-didáticos", "questões sobre o Ensino de Geografia" e "questões sobre os conhecimentos técnicos-científicos-geográficos".

Nas considerações finais, são apresentadas reflexões sobre a pesquisa desenvolvida.

\section{ENADE: O CURRÍCULO AVALIADO}

Antes de apresentar o ENADE como objeto de interpretação e investigação, é preciso compreender como este trabalho entende o termo currículo e porquê o ENADE representa o currículo avaliado.

Etimologicamente, a palavra "currículo" possui origem na palavra latina Scurrere, que significa correr, curso, carro de corrida ou pista de corrida. Assim, "currículo" pode ser interpretado como a noção de um curso a ser seguido ou apresentado. O uso do termo latino curriculum relacionado à sequência e à escolarização foi registrado pela primeira vez por volta de 1633 na Universidade de Glasgow, na Escócia (GOODSON, 2008).

A Revolução Industrial na Europa, que se iniciou na metade do século XVIII e se expandiu em países do Hemisfério Norte entre meados do século XIX e início do século XX, marcou no campo educacional a necessidade da escolarização 
institucional devido ao crescimento populacional, e a necessidade de mão-de-obra escolarizada para trabalhar nas indústrias, trazendo o problema de selecionar e organizar as matérias que deveriam ser ensinadas e, como consequência, ganhou maior força o surgimento de instituições educacionais estruturadas em sistema de salas de aula para atender, ensinar, supervisionar e controlar grupos maiores de crianças e adolescentes (GOODSON, 2008; SILVA, 2011).

É importante entender o momento histórico em que as instituições escolares e as decisões sobre o que deveria ou não ser ensinado começaram a ser delineadas, pois Sacristán (2000) afirma que o currículo é uma construção social, constituindo-se como um objeto social, histórico e cultural e, por esse motivo, é resultado de interesses de grupos sociais; assim, o currículo não deve ser encarado como algo dado ou neutro. Nas palavras do pesquisador espanhol:

O currículo, como projeto baseado num plano construído e ordenado, relaciona a conexão entre determinados princípios e uma realização dos mesmos, algo que se há de comprovar e que nessa expressão prática concretiza seu valor. É uma prática na qual se estabelece um diálogo, por assim dizer, entre agentes sociais, elementos técnicos, alunos que reagem frente a ele, professores que o modelam, etc. Desenvolver esta acepção do currículo como o âmbito prático tem o aplicativo de poder ordenar em torno deste discurso as funções que cumpre e o modo como as realiza, estudando-o processualmente: se expressa numa prática e ganha significado dentro de uma prática de algum modo prévio e que não é função apenas do currículo, mas de outros determinantes. É o contexto da prática, ao mesmo tempo que é contextualizado por ela (SACRISTÁN, 2000, p. 16).

Para Sacristán (2000), o currículo pode ser compreendido como um objeto construído e resultante de diversas forças que nele intervêm e se apresenta como a seleção e organização dos conhecimentos que serão ensinados nas instituições escolares.

Goodson (1998) ressalta que a escolha das disciplinas escolares e os processos de legitimação do que deve ou não ser ensinado nas instituições escolares não pode ser encarado como um processo neutro, uma vez que há disputas e negociações no interior das comunidades disciplinares que envolvem lutas políticas por recursos e poder.

Sacristán (2000) propõe um modelo de interpretação do currículo diferenciando seis fases ou níveis na objetificação do seu significado, que se inicia no processo de construção curricular, passa pela prática pedagógica e é finalizado na avaliação, sendo elas: 1) currículo prescrito, prescrições ou orientações expressas em instrumentos legais que indicam o que deve ser ensinado aos alunos; 2) currículo apresentado aos professores, interpretações e traduções do currículo prescrito feitas por diferentes agentes; 3) currículo moldado pelos professores, tradução que o professor realiza individualmente ou em grupo do currículo prescrito e o currículo apresentado aos professores e, a partir disso, delineia planejamentos pedagógicos; 4) currículo em ação, a concretização da ação pedagógica; 5) currículo realizado, são as aprendizagens dos estudantes e; 6) currículo avaliado, uma prática avaliadora com a imposição de critérios para o ensino do professor e a aprendizagem dos estudantes ao ressaltar determinados componentes em detrimento de outros.

A partir dessa noção, entende-se que o ENADE, que é uma avaliação externa e em larga escala organizada pelo Inep, uma autarquia do MEC, representa a sexta 
fase, ou nível da objetificação do significado do currículo proposto por Sacristán (2000), representando o currículo avaliado.

O ENADE avalia a Formação Geral e a Formação Específica. Em cada edição do ENADE, são publicadas portarias que são as matrizes de referência que definem o perfil profissional, os conteúdos e as habilidades e competências esperados de serem desenvolvidos no processo de formação do curso de graduação investigado pela avaliação padronizada.

O ENADE segue um calendário trienal. Desse modo, a área de Geografia foi avaliada nos anos de 2005, 2008, 2011, 2014 e 2017. De acordo com Jesus (2019) e Oliveira (2020), a análise dos textos das matrizes de referência orientadoras da prova do ENADE para o curso de Geografia nas edições de 2005, 2008 e 2011 não diferenciavam as carreiras de bacharelado e licenciatura em Geografia, uma vez que a orientação definia que o perfil profissional era o graduando em Geografia. A portaria de 2014 especificou que o licenciando em Geografia seria avaliado de forma diferente do bacharelando, seguindo a normativa referente ao curso de Pedagogia. No ano de 2017, pela primeira vez, o ENADE publicou matrizes de referência distintas para os cursos de licenciatura e bacharelado em Geografia.

Callai (2013) reforça que a distinção entre as formações do bacharelado e licenciatura é um importante passo para a valorização da formação docente. Para a professora:

É muito claro, entretanto, que no caso do professor está superado aquela proposição de que este não precisava dominar o conhecimento próprio da Geografia, na suposição equivocada de que o mais importante era a forma de ensinar. Hoje a ideia de que aquele que vai ser professor precisa saber de Geografia tanto quanto aquele que será o técnico ou bacharel, e mais que a afora saber da Geografia para saber do ensinar Geografia (CALLAI, 2013, p. 16).

Considerando que, para Sacristán (2000), o currículo avaliado também pode ser entendido como o currículo enfatizado, sendo o "currículo mais valorizado, a expressão da última concretização de seu significado para professores, que, assim evidenciam uma ponderação, e para alunos, que dessa forma, percebem através de que critérios são avaliados" (SACRISTÁN, 2000, p. 311), a não diferenciação nas matrizes de referência no perfil profissional das carreiras de bacharelado e licenciatura sugere menor valorização da formação do professor.

Para Jesus (2019), a partir da análise comparativa das matrizes de referência do ENADE para o curso de Geografia, é possível perceber que as heranças do "esquema 3+1" permaneceram fortemente presentes na organização da prova padronizada ao longo dos anos de 2005, 2008, 2011 e 2014, sendo que, na edição de 2017, foram publicadas duas diretrizes para os cursos de bacharelado em Geografia e licenciatura em Geografia, mostrando um avanço. Contudo, a maior parte das informações presentes nos textos apresentou a mesma redação, indicando que, nas matrizes de referência do ENADE 2017, o curso de licenciatura em Geografia ainda possui como característica ser muito parecido com o curso de bacharelado em Geografia, com a adição de alguns termos relacionados ao ensino e à didática. Jesus (2019) afirma que:

o fato de uma avaliação organizada pelo MEC legitimar que o professor de Geografia é um especialista bacharel que realiza poucas disciplinas da área educacional pode provocar a ausência de uma 
formação condizente com a futura área de atuação do professor de Geografia e do geógrafo (JESUS, 2019, p. 3980).

Entende-se que o "esquema $3+1$ " se aproxima do modelo dos conteúdos culturais-cognitivos, tendo em vista que a ênfase é dada ao domínio específico dos conteúdos da área de conhecimento correspondente à disciplina que será lecionada.

Vale ressaltar que, para Sacristán (2000), o currículo avaliado é indicado como uma última fase, mas não significa que é a mera confrontação com o currículo prescrito, uma vez que muitas vezes é o currículo enfatizado que norteia o currículo em ação.

Isso é importante pois consideram-se as Diretrizes Curriculares Nacionais para a Formação de Professores da Educação Básica (DCNs) como o currículo prescrito, que é um marco legal para a separação dos cursos de bacharelado e licenciatura, e estabelece que

A definição dos conhecimentos exigidos para a constituição de competências deverá, além da formação específica relacionada às diferentes etapas da educação básica, propiciar a inserção no debate contemporâneo mais amplo, envolvendo questões culturais, sociais, econômicas e o conhecimento sobre o desenvolvimento humano e a própria docência, contemplando: I - cultura geral e profissional; II conhecimentos sobre crianças, adolescentes, jovens e adultos, aí incluídas as especificidades dos alunos com necessidades educacionais especiais e as das comunidades indígenas; III conhecimento sobre dimensão cultural, social, política e econômica da educação; IV - conteúdos das áreas de conhecimento que serão objeto de ensino; V - conhecimento pedagógico; VI - conhecimento advindo da experiência (BRASIL, 2002).

Nesse sentido, as DCNs determinaram formalmente que a noção de que professor só aprende na prática fosse abandonada e, em seu lugar, o modelo pedagógico-didático fosse equilibrado com os conteúdos culturais-cognitivos, uma vez que a formação dos professores deveria englobar a cultura geral, a formação específica na área de conhecimento correspondente e a preparação pedagógicodidática.

Cabe, portanto, o seguinte questionamento: se o currículo prescrito representado pelas $\mathrm{DCN}$ s indica maior equilíbrio entre o modelo pedagógico-didático e o modelo dos conteúdos culturais-cognitivos, o currículo avaliado representado pelo ENADE segue a mesma linha?

Para responder a essa pergunta, as questões das edições do ENADE para a Formação Específica que avaliaram o curso de licenciatura em Geografia nos anos de 2005, 2008, 2011, 2014 e 2017 foram categorizadas.

A próxima seção explicará o processo de categorização dessas questões.

\section{METODOLOGIA}

Esta pesquisa adotou procedimentos de pesquisa qualitativa de análise de conteúdo por categorização baseados em Gibbs (2009) e Bardin (2016), sendo analisados cinco documentos (BRASIL, 2005; 2008; 2011; 2014; 2017).

Sobre codificação, Gibbs (2009) afirma que é um processo analítico presente na pesquisa qualitativa, que consiste na proposta metodológica de identificar passagens no texto que exemplifiquem alguma ideia temática, sendo que essa 
categorização pode ser construída a partir de conceitos presentes em estudos anteriores.

No caso desta pesquisa, os conceitos usados são os modelos de formação de professores propostos por Saviani (2009) - conteúdos culturais-cognitivos, em que há enfoque no domínio específico dos conteúdos da área; e pedagógico-didático com preocupação no ensino-aprendizagem.

Vale ressaltar que, embora o alvo desta pesquisa seja a organização curricular dos cursos de licenciatura em Geografia a partir do currículo avaliado, provas para a área de Geografia foram analisadas também. Isso aconteceu porque, nos anos de 2005 e 2008, as edições do ENADE reuniram na mesma avaliação as carreiras de bacharelado e licenciatura. Na edição de 2011, foram indicadas dez questões de múltipla-escolha que deveriam ser respondidas conforme o curso de licenciatura em Geografia ou bacharelado em Geografia. Em 2014 e 2017, foram aplicadas avaliações diferentes para os cursos de licenciatura e bacharelado em Geografia.

Bardin (2016) afirma que a análise categorial é uma técnica bastante utilizada na análise de conteúdo e funciona a partir do desmembramento do texto em categorias, permitindo a investigação dos temas ou a análise temática. Para identificar o modelo de formação de professores que o currículo avaliado sugere ao enfocar determinados conhecimentos em suas questões, foram elaboradas categorias de interpretação das questões.

Ao examinar um conjunto de questões de provas, foi possível verificar uma tipologia dos conhecimentos veiculados pelas perguntas. Para descrever as provas por meio de método comparativo entre semelhanças e diferenças, bem como por meio da aproximação com questões educacionais e pedagógicas, foram estabelecidas as seguintes categorias: 1) Questões sobre os conhecimentos pedagógicos-didáticos; 2) Questões sobre o Ensino de Geografia; 3) Questões sobre os conhecimentos técnicos-científicos-geográficos.

$\mathrm{Na}$ categoria questões sobre os conhecimentos pedagógicos-didáticos as questões exigem que o estudante demonstre seu conhecimento pedagógico-didático. Isso inclui o que amplamente pode ser categorizado como Didática Geral, bem como os problemas que estão dispostos diante de qualquer professor, independentemente de disciplina ou nível de ensino.

A Figura 1 apresenta uma questão que foi aplicada no ENADE 2005 para área de Geografia, do tipo asserção-razão, na qual o conteúdo exigido é relacionado à prática pedagógica de uma maneira ampla, uma vez que os conceitos de interdisciplinaridade e transversalidade não são restritos ao Ensino de Geografia.

Figura 1- Exemplo de questão da categoria questões sobre os conhecimentos pedagógicos-didáticos

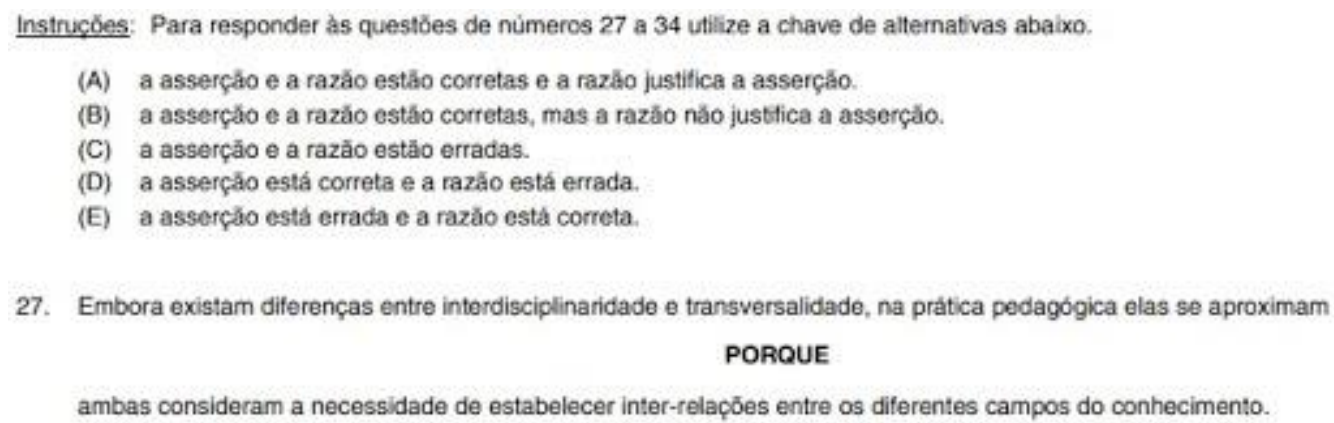

Fonte: Prova do ENADE - Área Geografia - 2005 (BRASIL, 2005). 
$\mathrm{Na}$ categoria questões sobre o Ensino de Geografia foram classificadas as questões que demandam que o estudante resolva uma situação problema envolvendo conhecimentos específicos sobre o Ensino de Geografia. Em termos de categorização do conhecimento, são as perguntas relativas ao que se poderia chamar de Didática específica de Geografia. Inclui dificuldades cognitivas e obstáculos próprios dos conceitos e explicações da Geografia escolar.

A Figura 2 exemplifica o que se acha dentro da categoria Ensino de Geografia. É do tipo resposta múltipla na qual é pedido que o estudante mobilize conhecimentos sobre o processo de ensino-aprendizagem em Geografia, especificamente sobre a diversidade étnico-racial.

Figura 2- Exemplo de questão da categoria questões sobre o Ensino de Geografia

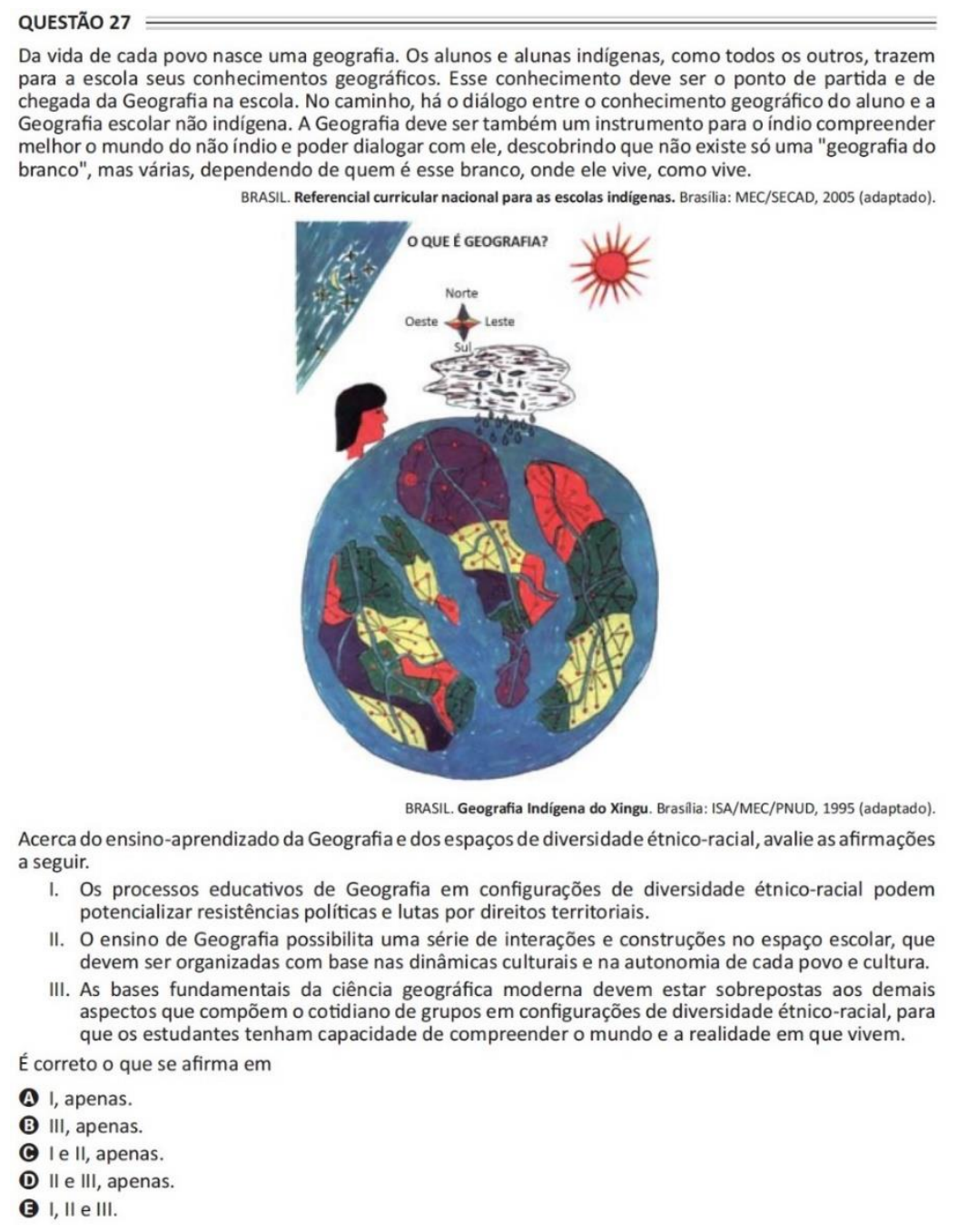

Fonte: Prova do ENADE - Licenciatura em Geografia - 2017 (BRASIL, 2017).

$\mathrm{Na}$ categoria questões sobre os conhecimentos técnicos-científicosgeográficos foram incluídas as questões que exigiam que o aluno mobilizasse conhecimentos geográficos (técnico-científico). Podem ser comparadas ao que Saviani (2009) denominou de conteúdos culturais-cognitivos.

$\mathrm{Na}$ Figura 3, foi selecionado um exemplo classificado na categoria "questões sobre os conhecimentos técnicos-científicos-geográficos", do tipo complementação simples. Apesar de o texto-base contextualizar uma situação em sala de aula, o conhecimento que o estudante deve mobilizar para respondê-la é sobre a resolução de problemas envolvendo escala. Essa questão foi escolhida para exemplificar que a 
simples menção à "aula de Geografia" não indica necessariamente que a questão exige conhecimentos sobre o Ensino de Geografia.

Figura 3- Exemplo de questão da categoria questões sobre conhecimentos técnicoscientíficos-geográficos

QUESTÃO 30

Durante uma aula de Geografia, o professor foi questionado por um grupo de estudantes do Ensino Médio sobre a distância entre Porto Alegre/Brasil e Mabrouk/Mali. Aproveitando o questionamento, o professor usou uma régua padrão e o mapa-múndi e retornou a seguinte pergunta ao grupo: “Considerando que este mapa foi construído na escala 1 : 32320000 e verificando que, no mapa, observa-se uma distância de 10 centímetros entre Porto Alegre e Mabrouk, qual a distância real em quilômetros entre as duas cidades em linha reta?"

A resposta correta à indagação do professor é

A 3232 .

B 6464 .

C 32320 .

(D) 64640 .

E 323200 .

Fonte: Prova do ENADE - Licenciatura em Geografia - 2017 (BRASIL, 2017).

Essa categorização permite verificar as características conservadas e alteradas ao longo das edições do ENADE que avaliaram o curso de licenciatura em Geografia e, a partir das quantidades das questões, é possível sugerir três conclusões, sendo elas:

I- Uma avaliação externa com maior quantidade de questões categorizadas como "questões sobre os conhecimentos técnicos-científicos-geográficos" sugere a enfatização no modelo de conteúdos culturais-cognitivos;

II- Uma avaliação externa com número de questões equilibradas entre "questões sobre os conhecimentos técnicos-científicos-geográficos", "questões sobre os conhecimentos pedagógicos-didáticos" e "questões sobre o Ensino de Geografia" pode indicar o modelo pedagógico-didático e a valorização da carreira docente;

III- Uma avaliação externa que possui maior quantidade de "questões sobre os conhecimentos pedagógicos-didáticos" do que "questões sobre o Ensino de Geografia" pode sugerir a permanência do "esquema 3+1".

Na próxima seção, serão apresentados os resultados dessas categorizações

\section{RESULTADOS: CATEGORIZAÇÃO DAS QUESTÕES DO ENADE}

Esta seção apresenta os resultados da categorização realizada por Oliveira (2020). Conforme apontado na seção anterior, as questões das edições do ENADE entre 2005 e 2017 que avaliaram o curso de licenciatura em Geografia - mesmo que o perfil do profissional não tenha diferenciado as carreiras de bacharel e licenciado em Geografia, como apontado por Jesus (2019) - são os alvos de interpretação e categorização. Na Tabela 1 há o resultado das categorizações por tipo de conhecimento. 
Tabela 1- Resultado das categorizações por tipo de conhecimento das questões do Enade para os cursos de licenciatura em Geografia

\begin{tabular}{|c|c|c|c|c|c|}
\hline $\begin{array}{c}\text { Tipo de } \\
\text { conhecimento }\end{array}$ & $\begin{array}{c}\text { Edição de } \\
2005 \\
\end{array}$ & $\begin{array}{l}\text { Edição de } \\
2008\end{array}$ & $\begin{array}{l}\text { Edição } \\
\text { de } 2011\end{array}$ & $\begin{array}{l}\text { Edição } \\
\text { de } 2014\end{array}$ & $\begin{array}{l}\text { Edição } \\
\text { de } 2017\end{array}$ \\
\hline $\begin{array}{l}\text { Questões sobre os } \\
\text { conhecimentos } \\
\text { pedagógicos- } \\
\text { didáticos }\end{array}$ & 3 & 0 & 5 & 5 & 5 \\
\hline $\begin{array}{lr}\text { Questões } & \text { sobre o } \\
\text { Ensino } & \text { de } \\
\text { Geografia } & \end{array}$ & 3 & 1 & 5 & 5 & 6 \\
\hline $\begin{array}{l}\text { Questões sobre os } \\
\text { conhecimentos } \\
\text { técnicos-científicos- } \\
\text { geográficos }\end{array}$ & 24 & 29 & 20 & 20 & 19 \\
\hline Total de questões & 30 & 30 & 30 & 30 & 30 \\
\hline
\end{tabular}

A partir da leitura da Tabela 1, é possível perceber que, em todas as edições do ENADE, ao menos uma questão sobre o Ensino de Geografia foi abordada, indicando uma tímida preocupação com a formação docente, mesmo quando a prova era a mesma para as carreiras de bacharelado e licenciatura em Geografia, como foi o caso das edições de 2005 e 2008.

A partir de 2014, foram aplicadas provas diferentes para as carreiras de bacharelado e licenciatura em Geografia, mostrando um avanço. Entretanto, a Tabela 1 indica que a quantidade de questões categorizadas como "questões sobre os conhecimentos técnicos-científicos-geográficos" foi superior às questões categorizadas como "questões sobre os conhecimentos pedagógicos-didáticos e "questões sobre o Ensino de Geografia", mostrando um desequilíbrio e sugerindo que o modelo dos conteúdos culturais-cognitivos foi enfatizado.

De modo geral a análise da Tabela 1 indica que as edições de 2005 e 2008 se aproximam mais do modelo dos conteúdos culturais-cognitivos, pois há enfoque no domínio específico dos conteúdos técnicos-científicos. Já as edições de 2011, 2014 e 2017 continuam com maior enfoque nos conteúdos técnicos-científicos, mas apresentam maior preocupação com a formação docente. aproximando-se mais do modelo pedagógico-didático. Entretanto, ainda se configurando com desequilíbrio.

As categorizações sugerem que as críticas feitas por Saviani e Libâneo (2015) para a formação dos professores continuam marcando fortemente a organização curricular dos cursos de licenciatura em Geografia no currículo avaliado sob a forma do ENADE.

\section{CONSIDERAÇÕES FINAIS}

A análise qualitativa e de conteúdo das questões do ENADE com a finalidade de investigar a organização dos currículos é de extrema relevância pois o ENADE, além de representar o currículo avaliado, faz parte da avaliação das Instituições de Ensino Superior (IES). Dessa forma, é esperado que as IES organizem suas grades curriculares conforme o que é cobrado no ENADE. 
Destaca-se que este trabalho não tem a intenção de responsabilizar o docente, mas de mostrar que a organização curricular que enfatiza os conhecimentos técnicoscientíficos em detrimento dos conhecimentos da formação docente é um problema histórico brasileiro.

Cabe ressaltar que o currículo prescrito - as DCNs - indica a valorização da formação pedagógica. Entretanto, as heranças do "esquema $3+1$ " e do modelo dos conteúdos culturais-cognitivos, como indicado por Saviani (2009), se mantém presentes ao longo das edições do ENADE para a área de Geografia. As mudanças presentes nas edições de 2014 e 2017 apontam um tímido avanço, mas ainda não suficiente para afirmar que o modelo pedagógico-didático é valorizado nas questões do ENADE para os cursos de licenciatura em Geografia.

Compreende-se que o ENADE pode ser um fator indutor de maior equilíbrio entre a formação técnico-científica e pedagógica dos novos professores mas, para isso ocorrer, é necessário alterar a ênfase expressa por meio das questões das provas, sendo necessário equilíbrio entre as "questões sobre os conhecimentos técnicos-científicos-geográficos", as "questões sobre os conhecimentos pedagógicosdidáticos" e as "questões sobre o Ensino de Geografia" para que, de fato, o currículo avaliado atenda ao modelo pedagógico-didático.

Portanto, embora sejam observados avanços na organização do currículo avaliado, é preciso que seja superada a ideia de que os conhecimentos técnicoscientíficos são hierarquicamente superiores aos conhecimentos pedagógicosdidáticos e referentes ao Ensino de Geografia.

\section{REFERÊNCIAS}

BARDIN, L. Análise de conteúdo. 1. ed. São Paulo: Edições 70, 2016.

BRASIL. Decreto-Lei no 1190, de 04 de abril de 1939. Dá organização à Faculdade Nacional de Filosofia. Diário Oficial da União, Seção 1, p. 7299, Rio de Janeiro, DF, 06 abr. 1939.

BRASIL, INEP. Prova ENADE 2005 Geografia. Portal INEP, 2005. Disponível em: https://download.inep.gov.br/download/enade/2005/provas/GEOGRAFIA.pdf. Acesso em: 31 jan. 2020.

BRASIL, INEP. Prova ENADE 2008 Geografia. Portal INEP, 2008. Disponível em: https://download.inep.gov.br/download/Enade2008_RNP/GEOGRAFIA.pdf. Acesso em: 31 jan. 2020.

BRASIL, INEP. Prova ENADE 2011 Geografia. Portal INEP, 2011. Disponível em: https://download.inep.gov.br/educacao_superior/enade/provas/2011/GEOGRAFIA.pd f. Acesso em: 31 jan. 2020.

BRASIL, INEP. Prova ENADE 2014 Geografia Licenciatura. Portal INEP, 2014. Disponível em:https://download.inep.gov.br/educacao_superior/enade/provas/2014/26_geografi a_licenciatura.pdf. Acesso em: 31 jan. 2020.

BRASIL, INEP. Prova ENADE 2017 Geografia Licenciatura. Portal INEP, 2017. Disponível 
em:https://download.inep.gov.br/educacao_superior/enade/provas/2017/26_GEOGR AFIA_LICENCIATURA_BAIXA.pdf. Acesso em: 31 jan. 2020.

CALLAI, H. C. A formação do profissional da Geografia: o professor. ljuí: Editora Unijuí, 2013.

GIBBS, G. Análise de dados qualitativos. Porto Alegre: Artmed, 2009.

FREITAS, L. C. et al. Avaliação Educacional: Caminhando na contramão. 2. ed. Petrópolis: Vozes, 2009.

JESUS, J. G. Para o Enade o "esquema 3+1" permanece na formação do professor de Geografia? In: ENCONTRO NACIONAL DE PRÁTICA DE ENSINO DE GEOGRAFIA, POLÍTICAS, LINGUAGENS E TRAJETÓRIAS, 14., Campinas, 29 jun. - 04 jul. 2019. Anais [...], Campinas: Universidade Estadual de Campinas, 2019, p. 3969 - 3981.

LIBANEO, J. C. Formação de Professores e Didática para Desenvolvimento Humano. Educação \& Realidade, Porto Alegre, v. 40, n. 2, p. 629-650, jun. 2015.

PONTUSCHKA, N. N. A formação inicial do professor de Geografia. In: PICONEZ,S. C. B. (Coord.). A prática de ensino e o estágio supervisionado. São Paulo: Papirus, 1991. p. 101-124.

PONTUSCHKA, N. N.; PAGANELLI T. I.; CACETE, N. H. (Orgs.). Para ensinar e aprender Geografia. 3. ed. São Paulo: Cortez, 2009.

SILVA, T. T. Documentos de identidade: uma introdução às teorias do currículo. Belo Horizonte: Autêntica, 2011.

SAVIANI, D. Formação de professores: aspectos históricos e teóricos do problema no contexto brasileiro. Revista brasileira de educação, Rio de Janeiro, v. 14, n. 40, p. 143-155, 2009.

SACRISTÁN, J. G. O currículo: uma reflexão sobre a prática. Porto Alegre: Artmed, 2000.

SCHEIBE, L. A Formação Pedagógica do Professor Licenciado - Contexto Histórico. Perspectiva, Florianópolis, v.1, n.1, p. 31 - 45, ago./dez. 1983.

MORAES, A. C. R. A contribuição social do ensino de Geografia. In: CICLO DE DEBATES E PALESTRAS SOBRE REFORMULAÇÃO CURRICULAR E ENSINO DE GEOGRAFIA, UERJ, 2002. Anais [...], Rio de Janeiro: UERJ, 2002, p.09-23.

OLIVEIRA, Jéssica Gomes de Jesus. Conteúdos culturais-cognitivos versus didático-pedagógicos na formação do professor de geografia a partir do currículo avaliado/ENADE. 2020. Dissertação (Mestrado em Ensino e História de Ciências da Terra), Universidade Estadual de Campinas, Campinas, 2020. 